\title{
A new approach to the design of complex all-pass IIR digital filters
}

\author{
Jong-Jy Shyu ${ }^{\mathrm{a}, *}$, Soo-Chang Pei ${ }^{\mathrm{b}}$ \\ "Department of Computer Science and Engineering, Tatung Institute of Technology, 40 Chungshan N. Rd., 3rd Sec. Taipei, Taiwan, 104, \\ $R O C$ \\ ${ }^{b}$ Department of Electrical Engineering, National Taiwan University, Taipei, Taiwan, ROC
}

Received 25 October 1993; revised 4 February 1994 and 22 April 1994

\begin{abstract}
A new method is proposed for designing complex all-pass IIR filters, the all-pass IIR filters with complex coefficients, in this paper. By minimizing the integration of certain square phase error over interested frequencies, an eigenvector of an appropriate real, symmetric and positive-definite matrix is computed to get the filter coefficients. The stability is achieved by specifying properly the desired phase specifications. If an appropriate iterative process is used, equiripple complex all-pass filter design can be obtained. The method is simple and the performance is comparable to the existing methods. Several examples are presented to demonstrate the effectiveness of the approach.
\end{abstract}

\section{Zusammenfassung}

Ein neues Verfahren zum Entwurf komplexwertiger rekursiver Allpaßfilter wird vorgeschlagen, d.h. für Filter unbegrenzter Impulsantwort mit komplexen Koeffizienten. Durch die Minimierung des quadratischen Mittelwertes geeigneter Phasenfehler im interessierenden Frequenzbereich gelangt man zur Bestimmung des Eigenvektors einer geeigneten reellen, symmetrischen, positiv-definitiven Matrix, aus dem man dann die Koeffizienten erhält. Stabilität wird durch die angemessene Vorgabe der Wunschphase erzielt. Durch die Anwendung eines passenden iterativen Vorgehens kann man komplexwertige IIR-Allpässe mit Equal-Ripple-Verhalten bekommen. Die Methode ist einfach, und die Leistungsfähigkeit ist vergleichbar mit bestehenden Verfahren. Etliche Beispiele werden vorgestellt, um die Wirksamkeit des Ansatzes zu demonstrieren.

\section{Résumé}

Une nouvelle méthode de calcul des filtres passe-tout IIR complexes, i.e. les filtres IIR avec coefficients complexes, est proposée dans cet article. En minimisant l'intégrale d'une certaine erreur quadratique de phase sur les fréquences d'intérêt, on calcule un vecteur propre d'une matrice appropriée, réelle, symétrique et définie positive, pour obtenir les coefficients du filtre. La stabilité est obtenue en spécifiant correctement les caractérisitiques désirées pour la phase. Si l'on utilise un processus itératif approprié, on peut obtenir un filtre passe-tout complexe à ondulation équilibrée. Cette méthode est simple et ses performances sont comparables à celles des méthodes existantes. Plusieurs exemples sont donnés, afin de démontrer l'efficacité de la méthode.

Keywords: Complex all-pass IIR digital filter; Equiripple all-pass filter

*Corresponding author. 


\section{Introduction}

In this paper, we will propose an effective method for designing complex IIR all-pass filters. The all-pass networks are usually used to equalize the nonlinear phase systems as well as to compensate the phase distortions produced by the communication channels. Also, they are widely used in multirate applications [13].

In the last decade, there have been several papers published concern real coefficient IIR all-pass filter design with their respective features $[5,2,1,14,8$, 6]. Recently, Ikehara et al. [6] extend their design algorithm to design further complex coefficient allpass networks by Remez algorithm [7]. Phase error is regarded as amplitude of complex error between the designed and the desired all-pass function. Then Remez exchange algorithm is applied to the amplitude of complex error, and it is approximated to be equiripple.

In this paper, we propose a least-squares approach to the design of phase of complex all-pass filters which can be used to equalize the nonlinear phase systems. And the complex filters are widely used in several applications such as orthogonal filters of the TDM-FDM transmultiplexers and the envelope detectors with the Hilbert transformer [4]. They are also useful in single-sideband modulation system for processing in-phase and quadrature signals in sonar and radar applications. The method is based on minimizing a quadratic measure of the phase error which is formulated as $A^{\mathrm{T}} Q A$ where $A$ is the coefficient vector, $\mathrm{T}$ denotes the transpose operation and $Q$ is a real symmetric and positive-definite matrix. The method is originally used to approximate the desired amplitudes of general multi-band filters [12]. By Rayleigh's principle $[12,9]$, the desired coefficient vector $A$ is just the eigenvector corresponding to the minimum eigenvalue of $Q$. The general formulation is described in Section 2. If an equiripple complex IIR all-pass digital filter is desired, a suitable weighting function is updated iteratively such that the maximum peak phase error is minimized. In Section 2, the design procedures will be proposed in detail. The method is simple and the performance is comparable to the existing methods. Several examples are presented to demonstrate the usefulness and effectiveness of the present approach in Section 3. Finally, the conclusions are given in Section 4.

\section{Formulation for the design of complex all-pass IIR digital filters}

For a complex all-pass filter with order $N$, the transfer function is characterized by

$$
\begin{aligned}
H(z) & =\frac{\sum_{n=0}^{N} a^{*}(N-n) z^{-n}}{\sum_{n=0}^{N} a(n) z^{-n}}=\frac{z^{-N} \sum_{n=0}^{N} a^{*}(n) z^{n}}{\sum_{n=0}^{N} a(n) z^{-n}} \\
& =\frac{z^{-N} D^{*}\left(1 / z^{*}\right)}{D(z)}
\end{aligned}
$$

where $\star$ denotes the complex conjugate operation and $a(n)$ 's are complex coefficients given by $a(n)=a_{\mathrm{R}}(n)+\mathrm{j} a_{\mathrm{I}}(n)$, in which $a_{\mathrm{R}}(n)$ and $a_{\mathrm{I}}(n)$ are the real part and the imaginary part of $a(n)$, respectively. Due to the unit magnitude gain for all-pass filters, the design problem is focused on the phase design. It has been shown that if the phase of $H(z), \arg \left(H\left(\mathrm{e}^{\mathrm{j} \omega}\right)\right)$, is monotone decreasing and spans a range of $2 \pi N$ as $\omega$ increases from 0 to $2 \pi$, then the all-pass filter is stable [11]. Also, for stablizing IIR all-pass filters a necessary and sufficient condition for the group delay $\tau(\omega)$ of $H(z)$ can be given by $[8,10]$

$\int_{0}^{2 \pi} \tau(\omega) \mathrm{d} \omega=2 \pi N \quad$ for $\tau(\omega)>0$,

where

$\tau(\omega)=-\frac{\mathrm{d}}{\mathrm{d} \omega} \arg \left(H\left(\mathrm{e}^{\mathrm{j} \omega}\right)\right)$.

So the stability for designing all-pass filters can be achieved by specifying the desired phase response properly.

From (1), the phase of $H(z)$ and the phase of $D(z), \arg \left(D\left(\mathrm{e}^{\mathrm{j} \omega}\right)\right)$, are related by

$\arg \left(H\left(\mathrm{e}^{\mathrm{j} \omega}\right)\right)=-N \omega-2 \arg \left(D\left(\mathrm{e}^{\mathrm{j} \omega}\right)\right)$,

so the phase design of $H(z)$ is equivalent to the phase design of $D(z)$ and we can restrict ourselves to the design of the denominator phase for designing IIR all-pass filters. That is to say, given the desired phase response $P_{H}(\omega)$ of $H(z)$, the design problem 
becomes to find properly the coefficient $a(n)$ 's such that the phase response of $D(z)$ approximates

$$
P_{D}(\omega)=-\frac{N \omega+P_{H}(\omega)}{2}, \quad 0 \leqslant \omega \leqslant 2 \pi
$$

From (1),

$$
\begin{aligned}
\tan \left(\arg \left(D\left(\mathrm{e}^{\mathrm{j} \omega}\right)\right)\right)=\frac{\sin \left(\arg \left(D\left(\mathrm{e}^{\mathrm{j} \omega}\right)\right)\right)}{\cos \left(\arg \left(D\left(\mathrm{e}^{\mathrm{j} \omega}\right)\right)\right)} \\
=\frac{-\sum_{n=0}^{N} a_{\mathrm{R}}(n) \sin (n \omega)+\sum_{n=0}^{N} a_{\mathrm{I}}(n) \cos (n \omega)}{\sum_{n=0}^{N} a_{\mathrm{R}}(n) \cos (n \omega)+\sum_{n=0}^{N} a_{\mathrm{I}}(n) \sin (n \omega)},
\end{aligned}
$$

so

$$
\begin{aligned}
& \sum_{n=0}^{N} a_{\mathrm{R}}(n)\left[\sin \left(\arg \left(D\left(\mathrm{e}^{\mathrm{j} \omega}\right)\right)\right) \cos (n \omega)\right. \\
&\left.+\cos \left(\arg \left(D\left(\mathrm{e}^{\mathrm{j} \omega}\right)\right)\right) \sin (n \omega)\right] \\
&+\sum_{n=0}^{N} a_{\mathrm{l}}(n)\left[\sin \left(\arg \left(D\left(\mathrm{e}^{\mathrm{j} \omega}\right)\right)\right) \sin (n \omega)\right. \\
&\left.\left.-\cos \left(\arg \left(D\left(\mathrm{e}^{\mathrm{j} \omega}\right)\right)\right) \cos (n \omega)\right)\right]=0 .
\end{aligned}
$$

Defining

$$
\begin{aligned}
& A=\left[\begin{array}{llll}
a_{\mathrm{R}}(0) & a_{\mathrm{R}}(1) & \cdots & a_{\mathrm{R}}(N)
\end{array}\right. \\
& \begin{array}{llll}
a_{\mathrm{I}}(0) & a_{\mathrm{I}}(1) & \cdots & \left.a_{\mathrm{I}}(N)\right]^{\mathrm{r}}
\end{array}
\end{aligned}
$$

and

$$
\begin{aligned}
& C(\omega)=\left[\begin{array}{llll}
c_{\mathrm{R}}(0) & c_{\mathrm{R}}(1) & \cdots & c_{\mathrm{R}}(N)
\end{array}\right. \\
& \left.c_{\mathrm{I}}(0) c_{1}(1) \cdots \cdots c_{\mathrm{I}}(N)\right]^{\mathrm{T}},
\end{aligned}
$$

where

$$
\begin{aligned}
c_{\mathrm{R}}(n)= & \sin \left(\arg \left(D\left(\mathrm{e}^{\mathrm{j} \omega}\right)\right)\right) \cos (n \omega) \\
& +\cos \left(\arg \left(D\left(\mathrm{e}^{\mathrm{j} \omega}\right)\right)\right) \sin (n \omega), \quad 0 \leqslant n \leqslant N
\end{aligned}
$$

and

$$
\begin{aligned}
c_{\mathrm{l}}(n)= & \sin \left(\arg \left(D\left(\mathrm{e}^{\mathrm{j} \omega}\right)\right)\right) \sin (n \omega) \\
& -\cos \left(\arg \left(D\left(\mathrm{e}^{\mathrm{j} \omega}\right)\right)\right) \cos (n \omega), \quad 0 \leqslant n \leqslant N .
\end{aligned}
$$

Eq. (7) can be represented in vector form as

$$
A^{\mathrm{T}} C(\omega)=0
$$

But it is impossible for finite $N$ to realize $D(z)$ such that the actual phase of $D(z)$ is exactly equiva- lent to the desired phase $P_{D}(\omega)$ of $D(z)$, and the problem we face is to replace $\arg \left(D\left(\mathrm{e}^{\mathrm{j} \omega}\right)\right)$ in $(10)$ and (11) by $P_{D}(\omega)$ and find a set of coefficients to minimize $A^{\mathrm{T}} \hat{C}(\omega)$ as much as possible, where

$$
\begin{aligned}
& \hat{C}(\omega)=\left[\begin{array}{llll}
\hat{c}_{\mathbf{R}}(0) & \hat{c}_{\mathrm{R}}(1) & \cdots & \hat{c}_{\mathrm{R}}(N)
\end{array}\right. \\
& \left.\hat{c}_{\mathrm{I}}(0) \hat{c}_{\mathrm{I}}(1) \cdots \hat{c}_{\mathrm{I}}(N)\right]^{\mathrm{T}}
\end{aligned}
$$

in which

$$
\begin{aligned}
& \hat{c}_{\mathrm{R}}(n)=\sin \left(P_{D}(\omega)\right) \cos (n \omega)+\cos \left(P_{D}(\omega)\right) \sin (n \omega), \\
& \quad 0 \leqslant n \leqslant N
\end{aligned}
$$

and

$$
\begin{aligned}
\hat{c}_{\mathrm{I}}(n) & =\sin \left(P_{D}(\omega)\right) \sin (n \omega)-\cos \left(P_{D}(\omega)\right) \cos (n \omega), \\
0 & \leqslant n \leqslant N .
\end{aligned}
$$

In this paper, we use the least-squares approach to find the coefficients with the phase error function as

$E=\int_{0}^{2 \pi} W(\omega)\left[A^{\mathrm{T}} \hat{C}(\omega)\right]^{2} \mathrm{~d} \omega=A^{\mathrm{T}} Q A$,

where $W(\omega)$ is a positive-valued weighting function and

$Q=\int_{0}^{2 \pi} W(\omega) \hat{C}(\omega) \hat{C}^{\mathrm{T}}(\omega) \mathrm{d} \omega$

which is obviously a real, symmetric and positive-definite matrix. By Rayleigh's principle [9], the desired filter coefficient vector is just the eigenvector corresponding to the minimum eigenvalue of $Q$, and can be calculated using the power method [12].

Sometimes, it is general to design equiripple phase error all-pass filters such that the peak phase error is minimized rather than to design those with least-squares integration of phase error. In order to achieve an equiripple complex all-pass filter in the Chebyshev sense, we can use the least-squares approach stated above iteratively by incorporating a suitable nonuniform weighting function $W(\omega)$ into the integrands. As to how to update $W(\omega)$, we adopt the iterative algorithm in [3] with a slight modification. The overall design procedures can be described as below:

Step 1. Specify the desired phase response $P_{H}(\omega)$ and the filter order $N$. Then the desired phase 
response of $D(z)$ can be obtained by (5). Set the initial weighting function as

$W(\omega)=1, \quad 0 \leqslant \omega \leqslant 2 \pi$.

Step 2. Calculate the matrix $Q$ by (17) and find the coefficient vector $A$, the eigenvector corresponding to the smallest eigenvalue of $Q$.

Step 3. Search for $\gamma_{i}, \delta$ and $\rho$ where

$\gamma_{i}$ is the $i$ th local maxima of the absolute phase error with phase ripple interval $\left(\omega_{i-1}, \omega_{i}\right]$,

$\delta$ is $\max \left\{\gamma_{i}\right\}$, the largest one of $\gamma_{i}$,

$\rho$ is $\min \left\{\gamma_{i}\right\}$, the smallest one of $\gamma_{i}$,

in which the absolute phase error is defined by

$E_{p}(\omega)=\left|P_{D}(\omega)-\arg \left(D\left(\mathrm{e}^{\mathrm{j} \omega}\right)\right)\right|$.

Step 4. Check whether the phase error is nearly equiripple by

$\frac{\delta-\rho}{\delta} \leqslant \varepsilon$,

where $\varepsilon$ is a preassigned very small positive constant. If the above condition is satisfied, then stop the process; otherwise go to the next step.

Step 5. Compute the unnormalized weighting function

$\hat{W}(\omega)=W(\omega) \gamma_{i}^{2}, \quad \omega_{i-1}<\omega \leqslant \omega_{i}, 1 \leqslant i \leqslant I$,

where $I$ is the number of phase ripples between 0 and $2 \pi$, and find its maximum value

$\delta_{W}=\max \{\hat{W}(\omega), 0 \leqslant \omega \leqslant 2 \pi\}$.

Then update the weighting function by

$W(\omega)=\frac{\hat{W}(\omega)}{\delta_{W}}, \quad 0 \leqslant \omega \leqslant 2 \pi$.

Go to Step 2.

Comparing with the Remez algorithm, the proposed algorithm provides another simple and useful method, and it will be proved that the method is effective for designing equiripple all-pass IIR filters through numerical examples in Section 3. Although the convergence of the above algorithm has not been proven, we have found that the algorithm converges very rapidly with several design examples. Also, the obtained IIR filters are stable in our design experience.

\section{Design examples}

In this section, four design examples are presented to illustrate the basic features of the proposed design method.

Example 1. A ninth-order full-band nonlinear delay all-pass digital filter is designed with the desired phase response given by

$P_{D}(\omega)=-9 \omega+2 \pi \sin \left(\frac{\omega}{2}\right), \quad 0 \leqslant \omega \leqslant 2 \pi$.

When $\varepsilon$ is set to 0.002 , Figs. 1 (a) and (b) show the phase response and absolute phase error, respectively, after 20 iterations. (In Fig. 1(b), the dotted line represents the phase error with peak value 0.1906472 after the first iteration.) The peak phase error is $0.1013352 \mathrm{rad}$ which is the same as that in [7]. The filter coefficients are listed in Table 1.

Example 2. In this example a tenth-order all-pass digital filter is designed. The desired phase response is given by

$P_{H}(\omega)=10 \pi\left\{\cos \left(\frac{\omega}{2}\right)-1\right\}, \quad 0 \leqslant \omega \leqslant 2 \pi$,

and $\varepsilon$ is also set to 0.002 . The obtained phase response after 11 iterations is given in Fig. 2(a) while Fig. 2(b) shows the absolute phase error. The peak error is $0.2295897 \mathrm{rad}$ which is almost the same as that in [7]. Also the filter coefficients are tabulated in Table 1.

Example 3. If the given phase specification changes suddenly in certain frequencies, the method can also be applied to design stable equiripple all-pass filters. For example, when $N=10$,

$$
P_{D}(\omega)= \begin{cases}9 \pi\{\cos (\omega / 2)-1\}, & 0 \leqslant \omega<\pi, \\ -10 \pi, & \omega=\pi, \\ 9 \pi\{\cos (\omega / 2)-1\}-2 \pi, & \pi<\omega \leqslant 2 \pi\end{cases}
$$

and $\varepsilon$ is preset to 0.01 , the phase response and absolute phase error after 14 iterations are shown in Figs. 3(a) and (b), respectively. The peak phase error is 0.2301555 and the filter coefficients are listed in Table 2. 

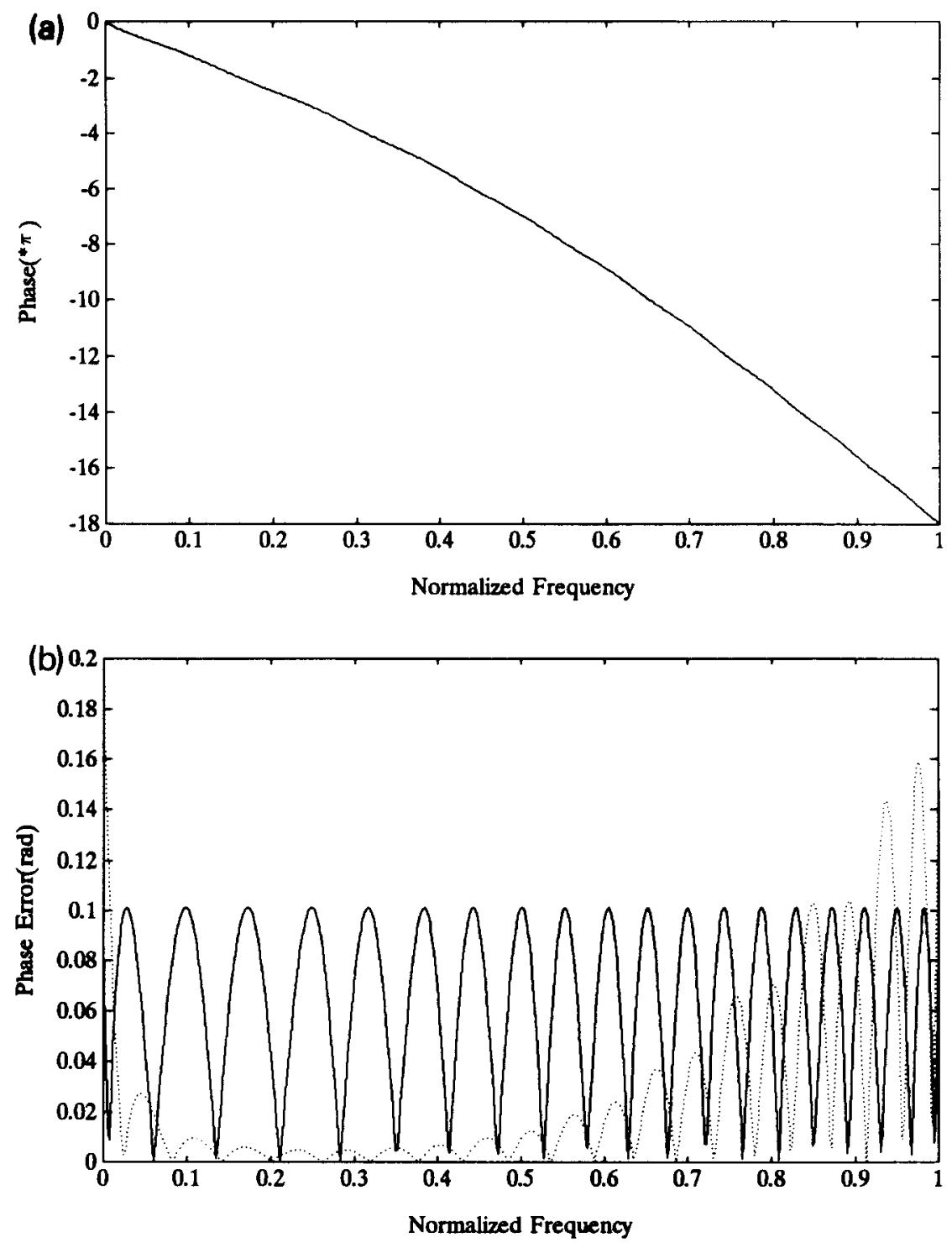

Fig. 1. Example 1: Design of a ninth-order full-band equiripple all-pass filter. (a) Phase response. (b) Absolute phase error. (Dotted line: phase error after the first iteration.)

Table 1

The filter coefficients $a(n)$ in Examples 1 and 2

\begin{tabular}{rrl}
\hline$n$ & Example 1 & Example 2 \\
\hline 0 & $2.1033035 \mathrm{e}-01+\mathrm{j} 4.6037804 \mathrm{e}-01$ & $-6.6018644 \mathrm{e}-02+\mathrm{j} 4.0940279 \mathrm{e}-07$ \\
1 & $-6.1443030 \mathrm{e}-01+\mathrm{j} 2.8079262 \mathrm{e}-01$ & $-2.2002738 \mathrm{e}-01+\mathrm{j} 2.3886372 \mathrm{e}-06$ \\
2 & $-3.1076109 \mathrm{e}-01-\mathrm{j} 3.5348146 \mathrm{e}-01$ & $-3.8852931 \mathrm{e}-01+\mathrm{j} 6.6162869 \mathrm{e}-06$ \\
3 & $5.3777297 \mathrm{e}-02-\mathrm{j} 2.2331145 \mathrm{e}-01$ & $-4.8614397 \mathrm{e}-01+\mathrm{j} 1.1594916 \mathrm{e}-05$ \\
4 & $6.7304885 \mathrm{e}-02-\mathrm{j} 6.2407320 \mathrm{e}-02$ & $-4.8594553 \mathrm{e}-01+\mathrm{j} 1.4667442 \mathrm{e}-05$ \\
5 & $2.9364535 \mathrm{e}-02-\mathrm{j} 1.8815762 \mathrm{e}-02$ & $-4.1356633 \mathrm{e}-01+\mathrm{j} 1.4491874 \mathrm{e}-05$ \\
6 & $6.7684633 \mathrm{e}-03-\mathrm{j} 1.2128184 \mathrm{e}-02$ & $-3.0942484 \mathrm{e}-01+\mathrm{j} 1.1423992 \mathrm{e}-05$ \\
7 & $-2.2768052 \mathrm{e}-03-\mathrm{j} 2.5613244 \mathrm{e}-02$ & $-2.0393990 \mathrm{e}-01+\mathrm{j} 6.7915159 \mathrm{e}-06$ \\
8 & $2.6485635 \mathrm{e}-02-\mathrm{j} 3.2360585 \mathrm{e}-02$ & $-1.1385784 \mathrm{e}-01+\mathrm{j} 2.6255749 \mathrm{e}-06$ \\
9 & $2.7574396 \mathrm{e}-02+\mathrm{j} 1.2586640 \mathrm{e}-02$ & $-4.8229243 \mathrm{e}-02+\mathrm{j} 4.5061690 \mathrm{e}-07$ \\
10 & & $-1.1552334 \mathrm{e}-02-\mathrm{j} 3.0727127 \mathrm{e}-08$ \\
\hline
\end{tabular}



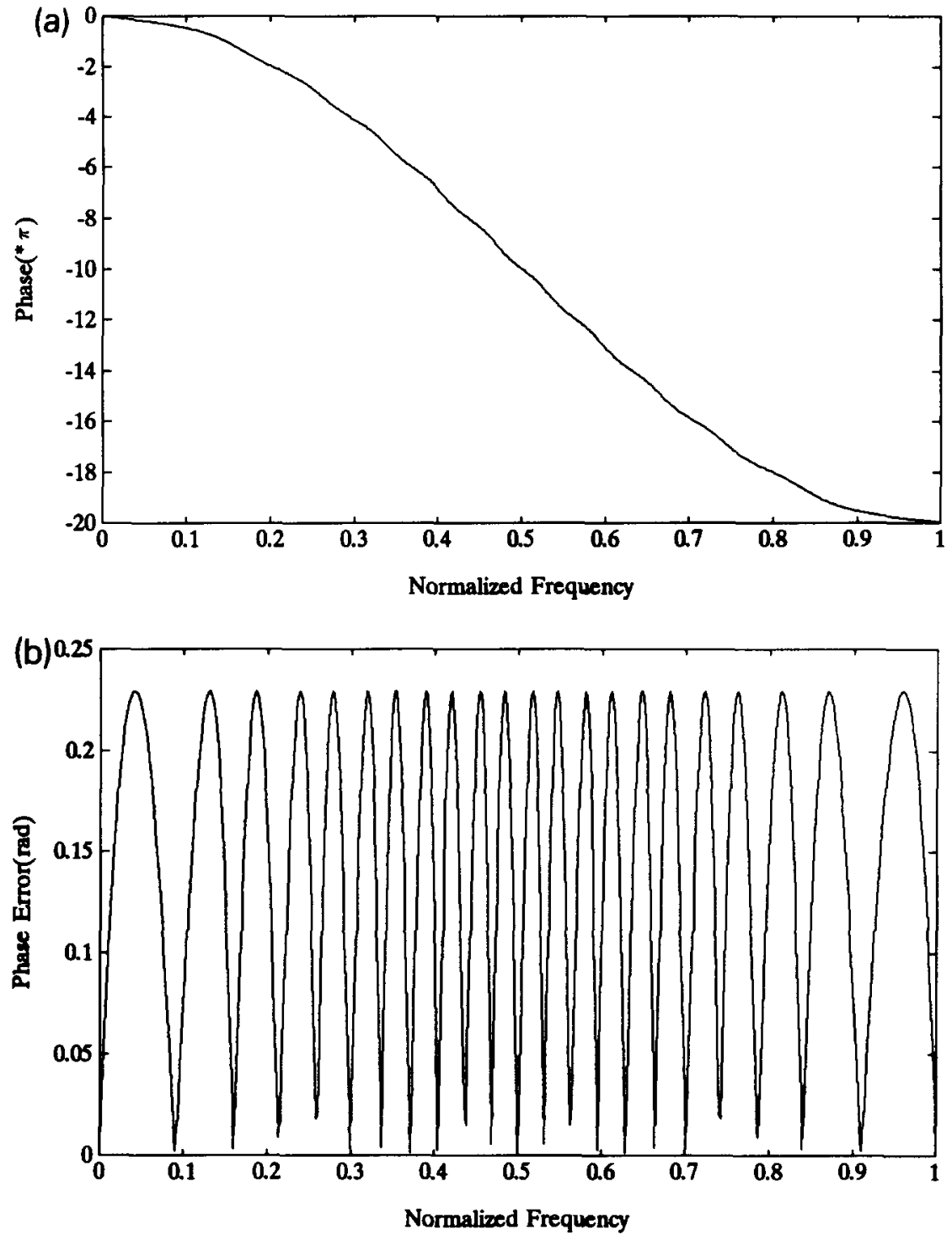

Fig. 2. Example 2: Design of a tenth-order full-band equiripple all-pass filter. (a) Phase response. (b) Absolute phase error.

Table 2

The filter coefficients $a(n)$ in Examples 3 and 4

\begin{tabular}{rlr}
\hline$n$ & Example 3 & \multicolumn{1}{l}{ Example 4} \\
\hline 0 & $-4.7672703 \mathrm{e}-02-\mathrm{j} 1.6737634 \mathrm{e}-06$ & $1.8971147 \mathrm{e}-01+\mathrm{j} 3.8283560 \mathrm{e}-01$ \\
1 & $-1.9066264 \mathrm{e}-01-\mathrm{j} 4.3791938 \mathrm{e}-06$ & $6.3593991 \mathrm{e}-01+\mathrm{j} 2.1450698 \mathrm{e}-01$ \\
2 & $-3.7162499 \mathrm{e}-01-\mathrm{j} 3.8121545 \mathrm{e}-06$ & $4.7230449 \mathrm{e}-01-\mathrm{j} 2.3404715 \mathrm{e}-01$ \\
3 & $-4.8936296 \mathrm{e}-01+\mathrm{j} 2.3704716 \mathrm{e}-06$ & $8.8212458 \mathrm{e}-02-\mathrm{j} 2.6151890 \mathrm{e}-01$ \\
4 & $-4.9966538 \mathrm{e}-01+\mathrm{j} 6.1495303 \mathrm{e}-06$ & $-4.8124016 \mathrm{e}-02-\mathrm{j} 9.7113719 \mathrm{e}-02$ \\
5 & $-4.2584031 \mathrm{e}-01-\mathrm{j} 3.9805764 \mathrm{e}-06$ & $-3.2263713 \mathrm{e}-02-\mathrm{j} 1.0882776 \mathrm{e}-02$ \\
6 & $-3.1441323 \mathrm{e}-01-\mathrm{j} 2.4184307 \mathrm{e}-05$ & $-7.9872832 \mathrm{e}-03+\mathrm{j} 3.9580417 \mathrm{e}-03$ \\
7 & $-2.0157212 \mathrm{e}-01-\mathrm{j} 3.5022507 \mathrm{e}-05$ & $-6.3933740 \mathrm{e}-04+\mathrm{j} 1.8954169 \mathrm{e}-03$ \\
8 & $-1.0719617 \mathrm{e}-01-\mathrm{j} 2.6484882 \mathrm{e}-05$ & $1.7439370 \mathrm{e}-04+\mathrm{j} 3.5192461 \mathrm{e}-04$ \\
9 & $-4.1680293 \mathrm{e}-02-\mathrm{j} 1.0507405 \mathrm{e}-05$ & $6.4951224 \mathrm{e}-05+\mathrm{j} 2.1908551 \mathrm{e}-05$ \\
10 & $-8.5503525 \mathrm{e}-03-\mathrm{j} 1.6808389 \mathrm{e}-06$ & $9.6384362 \mathrm{e}-06-\mathrm{j} 4.7762293 \mathrm{e}-06$ \\
11 & & $4.8408161 \mathrm{e}-07-\mathrm{j} 1.4351317 \mathrm{e}-06$ \\
12 & & $-7.4858870 \mathrm{e}-08-\mathrm{j} 1.5105132 \mathrm{e}-07$ \\
\hline
\end{tabular}



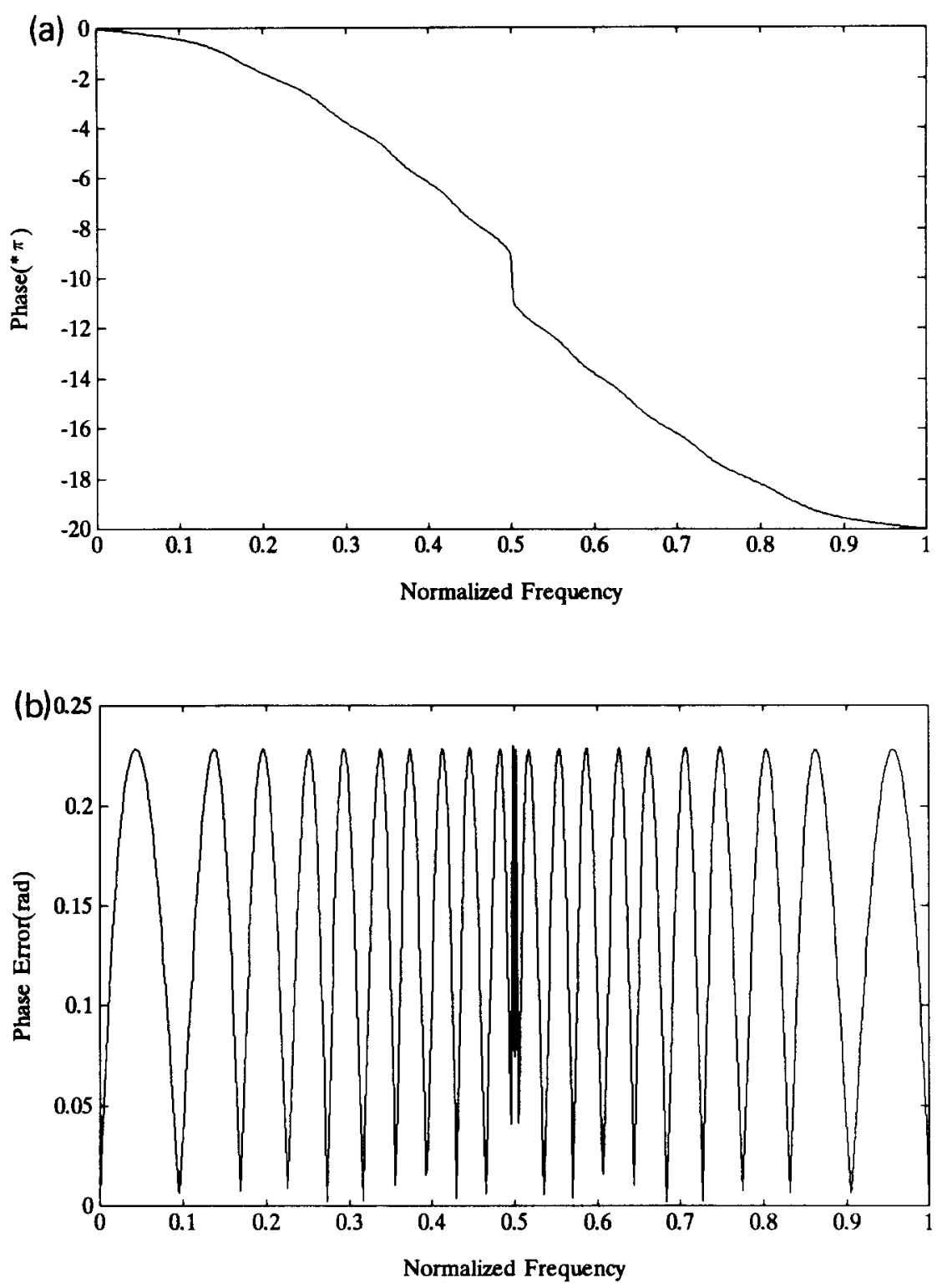

Fig. 3. Example 3: Design of a tenth-order full-band equiripple all-pass filter. (a) Phase response. (b) Absolute phase error.

Example 4. Sometimes, the desired group delay is given rather than the phase specification. For example, a twelfth-order all-pass filter is designed with

$\tau(\omega)=12+\pi \sin (\omega-\pi / 4), \quad 0 \leqslant \omega \leqslant 2 \pi$.
The corresponding desired phase by (3) is

$$
\begin{aligned}
& P_{D}(\omega)=-12 \omega+\pi \cos (\omega-\pi / 4)+c, \\
& 0 \leqslant \omega \leqslant 2 \pi,
\end{aligned}
$$

where $c$ is ay constant. If $c=-(\sqrt{2} / 2) \pi$ and $\varepsilon=0.01$ are chosen, Figs. 4(a) and (b) show the 

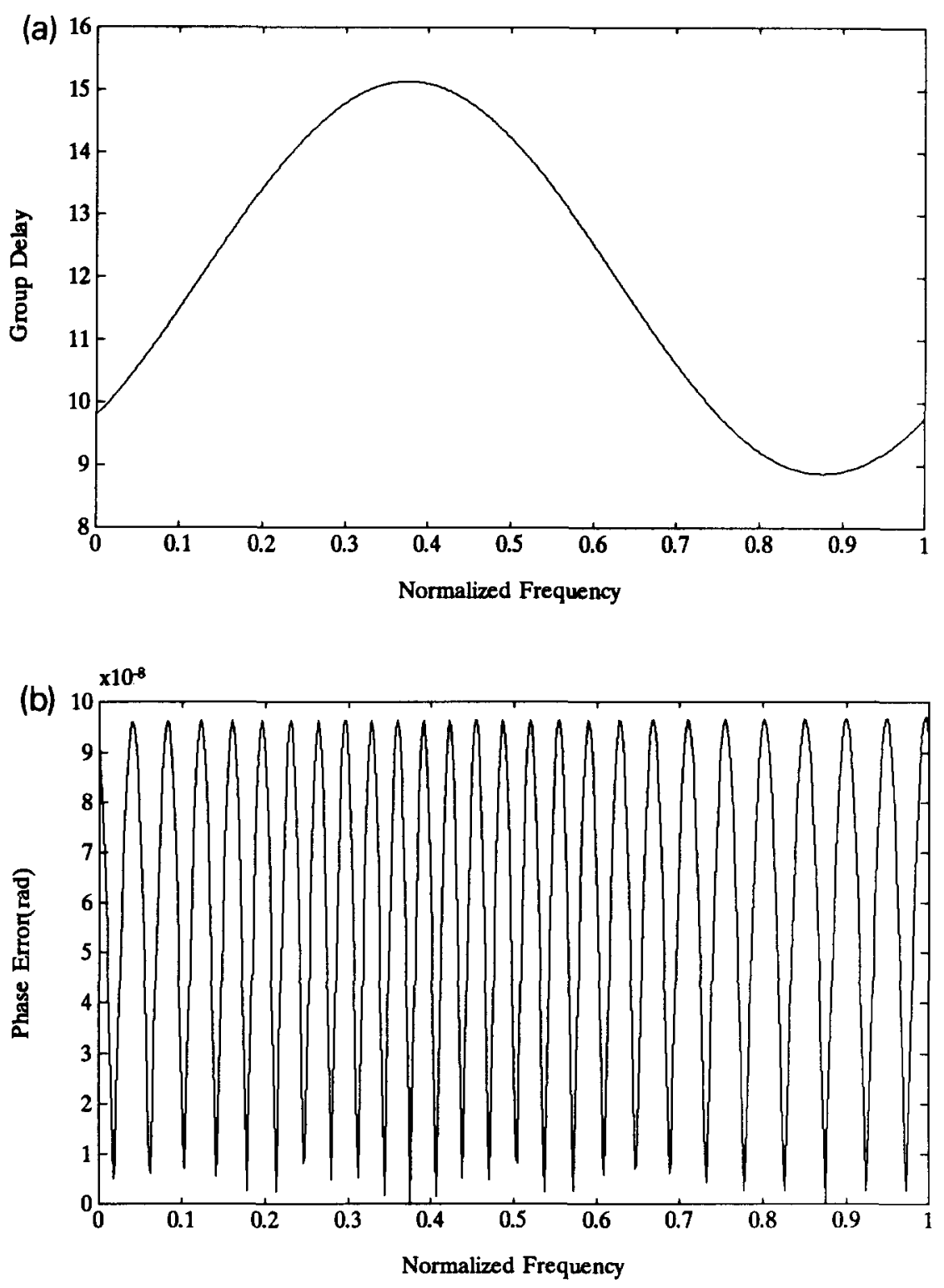

Fig. 4. Example 4: Design of a twelfth-order full-band equiripple all-pass filter. (a) Phase response. (b) Absolute phase error.

delay response and phase error respectively after 23 iterations. The peak phase error is $9.7059 \times 10^{-8}$ and the filter coefficients are tabulated in Table 2.

\section{Conclusions}

In this paper, an effective least-squares approach has been proposed for designing complex IIR all- pass digital filters. By formulating the phase error function over interested frequencies into the form $A^{\mathrm{T}} Q A$ where $A$ is the coefficient vector and $Q$ is a real, symmetric and positive-definite matrix, the desired solution is just the eigenvector corresponding to the smallest eigenvalue of $Q$. The stability is achieved by specifying properly the phase specifications. In order to achieve equiripple complex allpass filters, an iterative weighting least-squares 
approach has been used such that the maximum phase error is minimized. Comparing with the existing methods, the method is simple and effective.

\section{References}

[1] P.A. Bernhardt, "Simplified design of high-order recursive group-delay filters", IEEE Trans. Acoust. Speech Signal Process., Vol. 28, October 1980, pp. 498-503.

[2] F.J. Brophy and A.C. Salazar, "Two design techniques for digital phase network", Bell System Technical J., Vol. 54, April 1975, pp. 767-781.

[3] C.Y. Chi and Y.T. Kou, "A new self-initiated optimum WLS approximation method for the design of linear phase FIR digital filters", Proc. IEEE Internat. Symp. on Circuits and Systems, June 1991, pp. 168-171.

[4] T.H. Crystal and L. Ehrman, "The design and applications of digital filters with complex coefficients", IEEE Trans. Audio Electroacoust., Vol. 16, September 1968, pp. 315-320.

[5] A.G. Deczky, "Synthesis of recursive digital filters using the minimum p-error criterion", IEEE Trans. Audio Electroacoust., Vol. 20, October 1972, pp. 257-263.

[6] M. Ikehara. M. Funaishi and H. Kuroda, "Design of all-pass networks using Remez algorithm", Proc. IEEE Internat. Symp. on Circuits and Systems, 1991.
[7] M. Ikehara, M. Funaishi and H. Kuroda, "Design of complex all-pass networks using Remez algorithm", IEEE Trans. Circuits and Systems-II, Vol. 39, August 1992, pp. $549-556$.

[8] Z. Jing, "A new method for digital all-pass filter design", IEEE Trans. Acoust. Speech Signal Process., Vol. 35. November 1987, pp. 1557-1564.

[9] B. Nobel and J.W. Daniel, Applied Linear Algebra, Prentice-Hall, Englewoods Cliffs, NJ, 1977.

[10] L.R. Rabiner and B. Gold, Theory and Application of Digital Signal Processing, Prentice-Hall, Englewood Cliff, NJ, 1975.

[11] P.P. Vaidyanathan, Multirate Systems and Filter Banks, Prentice-Hall, Englewoods Cliffs, NJ, 1993.

[12] P.P. Vaidyanathan and T.Q. Nguyen, "Eigenfilter: a new approach to least-squares FIR filter design and applications including Nyquist filters", IEEE Trans. Circuits and Systems, Vol. 34, January 1987, pp. 11 23 .

[13] P.P. Vaidyanathan, P.A. Regalia and S.K. Mitra, "Design of doubly-complementary IIR digital filters using a single complex allpass filters, with multirate applications", IEEE Trans. Circuits and Systems, Vol. 34, April 1987, pp. 378-388.

[14] B. Yegnanarayana, "Design of recursive group-delay filters by autoregressive modeling", IEEE Trans. Acoust. Speech Signal Process., Vol. 30, August 1982 , pp. 632637 . 